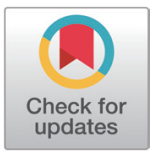

Received: May 8, 2020

Revised: Jul 26, 2020

Accepted: Nov 2, 2020

\#These authors contributed equally to this work.

${ }^{*}$ Corresponding author

Sang-Hoon Lee

Animal Genetic Resources Research

Center, National Institute of Animal

Science, Rural Development

Administration, Hamyang 50000, Korea.

Tel: +82-55-960-3540

E-mail: sanghoon@korea.kr

Copyright $@ 2021$ Korean Society of

Animal Sciences and Technology.

This is an Open Access article

distributed under the terms of the

Creative Commons Attribution

Non-Commercial License (http://

creativecommons.org/licenses/by-

nc/4.0/) which permits unrestricted

non-commercial use, distribution, and

reproduction in any medium, provided

the original work is properly cited.

ORCID

Kwan-Woo Kim

https://orcid.org/0000-0003-2729-2181

Jinwook Lee

https://orcid.org/0000-0001-9019-1653

Keun Jung Kim

https://orcid.org/0000-0003-2340-8319

Eun-Do Lee

https://orcid.org/0000-0002-2842-6041

Sung Woo Kim

https://orcid.org/0000-0001-8521-3010

Sung-Soo Lee

https://orcid.org/0000-0003-1255-9509

\section{Estrus synchronization and artificial insemination in Korean black goat (Capra hircus coreanae) using frozen-thawed semen}

\author{
Kwan-Woo Kim ${ }^{1 \#}$, Jinwook Lee ${ }^{1 \#}$, Keun Jung Kim², Eun-Do Lee ${ }^{1}$, \\ Sung Woo Kim ${ }^{1}$, Sung-Soo Lee ${ }^{1}$ and Sang-Hoon Lee ${ }^{1 *}$
}

${ }^{1}$ Animal Genetic Resources Research Center, National Institute of Animal Science, Rural Development Administration, Hamyang 50000, Korea

${ }^{2}$ Institute of Chungnam Livestock Research, Cheongyang 33350, Korea

\section{Abstract}

Presently, there is an increased demand for livestock products all over the world which has led to more devotion on improving livestock population. Although goats have been bred for a long time in Korea, but there is not much research conducted on traditional Korean black goat (Capra hircus coreanae) compared to other livestock populations. Mutton consumption has been dramatically changing from medicinal use to edible meat and this trend directs the black goat populations declining and also mutton import quantities are increasing consistently. The present study introduced a new estrus synchronizing technique with subsequent artificial insemination (Al) for Korean black goats to enable crossbreeding with non-native breeds for the small or subsistent farmers. Our data highlighted that, the percentage of motile sperm from the electro-ejaculated samples declined significantly after freezing and melting. In addition, the sperm motility significantly declined with regard to sperm incubation period $(0,5,60$, and $120 \mathrm{~min}$ at $\left.37^{\circ} \mathrm{C}\right)$ and was negatively correlated $(64.2 \pm 7.9 \%, 63.3 \pm 5.8 \%, 49.9 \pm 6.3 \%$, and $35.9 \pm 7.6 \%$, respectively) in frozen-thawed sperm samples. Moreover, the E2 levels were unchanged even $24 \mathrm{~h}$ after controlled internal drug releas (CIDR) withdrawal. But, $48 \mathrm{~h}$ and $72 \mathrm{~h}$ after CIDR removal, E2 levels increased significantly. These data helps us to consider the two time points for $\mathrm{Al}$; CIDR removal after $24 \mathrm{~h}$, at which E2 decreases, and after $48 \mathrm{~h}$, as the time at which progesterone increases. Additionally, the Al after $48 \mathrm{~h}$ of CIDR removal group exhibited significantly higher pregnancy and parturition rates $(42.9 \%)$ compared to Al after $24 \mathrm{~h}$ after CIDR removal $28.6 \%$ group. In conclusion, these studies will propose an optimal estrus synchronisation process with subsequent timing of $\mathrm{Al}$ and also will promote the Korean black goat breeding industry.

Keywords: Artificial insemination, Estrus synchronization, Frozen-thawed semen, Korean black goat 
Sang-Hoon Lee

https://orcid.org/0000-0003-4836-7402

\section{Competing interests}

No potential conflict of interest relevant to this article was reported.

Funding sources

This research was supported by the "Cooperative Research Program for Agriculture Science \& Technology Development (Project No. PJ01431502)" and Fellowship Program of National Institute of Animal Science (Rural Development Administration, Korea).

Acknowledgements

Not applicable.

Availability of data and material Upon reasonable request, the datasets of this study can be available from the corresponding author.

\section{Authors' contributions}

Conceptualization: Kim KW, Lee J.

Data curation: Kim KW, Lee J.

Formal analysis: Kim KW, Lee J.

Methodology: Kim KW, Lee ED, Kim SW.

Validation: Kim KW, Kim KJ.

Investigation: Kim KW, Lee J.

Writing - original draft: Kim KW.

Writing - review \& editing: Lee SS, Lee SH.

Ethics approval and consent to participate All experimental procedures were reviewed and approved by the Institutional Animal Care and Use Committee of the National Institute of Animal Science, Korea (No. 2019-329). This article does not require IRB/IACUC approval because there are no human and animal participants.

\section{INTRODUCTION}

In order to develop a promising breeding line to mitigate the increased demand of livestock products assisted reproductive technologies (ARTs) like as, semen cryopreservation, estrus synchronization, and artificial insemination (AI) have increased dramatically in the last decades [1]. Semen cryopreservation or freezing is usually used to reserve the germline of certain biologically, scientifically or economically valuable males, including livestock or endangered animal populations. Semen cryopreservation methods are species specific and therefore, semen cryopreservation methods have been established for a limited number of species because significant reduction in sperm motility and viability post-thawing (in comparison to freshly collected samples). Conservation of the Korean black goat (Capra hircus coreanae) which is the only native species in the Korean animal breeding industry with predominantly (80\%) black fur. The Korean black goat population contains roughly 348,776 individuals disseminated among approximately 11,860 farms, constituting the majority of small ruminants in Korea. The multiple farming methods like commercial and subsistent goat farms are often upheld on a small scale. Goat production, despite having a long history in Korean agriculture, has grown more slowly compared to other livestock species because of its poor segment in the food supply market. Recently, Korean black goat meat has gained popularity among the people and is on equivalence with beef, pork, and chicken.

To improve the efficiency of natural reproduction in goats, several assisted-ARTs have been developed, including semen cryopreservation, AI, and estrus synchronization. However, their efficiency is low because they are simply modifications of the processes used originally in bovines.

Goats exhibit seasonal reproductive cycles that can be controlled using different methods of estrus synchronization [2], which is a simple, cost-effective, and significant method for AI in goat breeding. In addition, it is a key factor in the management of reproduction [2,3]. As observed in other ruminants, the breed, feed management, and environment can influence goat estrus synchronization. To date, estrus synchronization protocols optimized for cattle breeding have been used to breed small ruminants $[4,5]$.

Goat reproduction either commercially or in small scale circumstances depends mainly on estrus synchronization, ovulation, and subsequent AI to be performed within a fixed time [6]. Commonly, the basis for estrus synchronisation is to increase the population rate during estrus or anestrus periods [7]. The synchronisation technique proposed the opportunity to increase the reproductive efficiency of an animal, as it permits mating or $\mathrm{AI}$ at a predetermined time. Moreover, it decreases the time needed for the recognition of estrus.

Several techniques have been recognized for goat estrus synchronization $[5,8,9]$. Progestogen administration is usually used either alone or in combination with other hormones [10]. Synchronization methods based on progesterone (P4), prostaglandin $\mathrm{F}_{2 \alpha}\left(\mathrm{PGF}_{2 \alpha}\right)$, and equine chorionic gonadotropin (eCG) have shown promising outcomes for detecting estrus [11]. First, gonadotropin-releasing hormone $(\mathrm{GnRH})$ is injected for estrus synchronization, resulting in the release of follicular stimulating hormone (FSH) and a surge of luteinizing hormone (LH) from the anterior pituitary gland. The administration of PGF $2 \alpha$ then induces regression of the corpus luteum or luteinized follicle. Then, a new dominant follicle is prepared for ovulation, which is triggered by the second $\mathrm{GnRH}$ administration [12,13]. Alternatively, estrus and ovulation can be synchronized by sponge-eCG in goats [5]. To improve the pregnancy rate of Korean black goats, several previous reports have been described the efficacy of controlled internal drug release (CIDR) treatments [14-16]. however, the effect of CIDR on estrus synchronization in Korean black goats has not been studied yet.

Although several studies have attempted to improve the breeding efficiency and reproductive 
techniques but only a few studies have been conducted in Korean black goats [10,17]. Therefore, the need for techniques that are suitable and appropriate for Korean black goats has emerged as a major research interest. Therefore, the present study was designed to standardize the optimal estrus synchronisation approaches with timing of AI through hormonal evaluation (P4 and estrogen [E2]) after estrus synchronization, and also semen quality evaluation post cryopreservation by using CIDR protocol to improve the chances of pregnancy in Korean black goat.

\section{MATERIALS AND METHODS}

\section{Experimental design}

Experiments were carried out during seasonal anestrus. Goats were kept under intensive care and management. The 21 female Korean black goats (C. bircus coreanae) with number of parity (2-3) and average body weight: $36 \mathrm{~kg}$ were used in this experiment. All part of the experiments was performed in accordance with the Guidelines for the Care and Use of Experimental Animals (National Institute of Animal Science, Wanju, Korea). All of the techniques and experimental procedures were conducted according to the Rural Development Administration, under the National Institute of Animal Science, Korea and received approval from the Ethical Committee on Animal Experiments (Approval Number: 2019-320). Concentrated fodder feed (maximum quantity: $1.8 \%$ body weight) was provided once daily to the experimental animals. Over the experimental period bulk forage and water were supplied ad libitum. Semen was collected via electro-ejaculation and preserved using a conventional and simple freezing method. Pre- and postfreezing semen was analyzed using computer-assisted sperm analysis (CASA). AI was performed after estrus synchronization through CIDR insertion protocol. Additionally, blood P4 and E2 levels were analyzed to determine the optimal AI time in estrus-synchronized Korean black goats.

\section{Semen collection and cryopreservation}

A Lane Ram Ejaculator (HeatWatch, RAU immobilizer, model number IM2000) with a rechargeable electric stimulator was used for semen collection. The probe was lubricated, inserted into the rectum, and semen was collected by applying 3-4 V for 4-5 s, 2-3 times. On average, ejaculation was achieved after three stimulations, and the semen samples were collected in $50-\mathrm{mL}$ tubes (BD Falcon, Corning, NY, USA) placed at the end-point of the penis. The electro-ejaculated semen was transported to the laboratory within 15 min with semen washing media (SWM). The SWM was composed of $\mathrm{NaCl} 130 \mathrm{mM}, \mathrm{KCl} 5.1 \mathrm{mM}$, glucose $10.54 \mathrm{mM}, \mathrm{KH}_{2} \mathrm{PO}_{4} 1.19 \mathrm{mM}$, $\mathrm{Na}_{2} \mathrm{HPO}_{4} 9.86 \mathrm{mM}, \mathrm{MgSO}_{4} \cdot 7 \mathrm{H}_{2} \mathrm{O} 1.47 \mathrm{mM}$, and $\mathrm{CaCl}_{2} \cdot 2 \mathrm{H}_{2} \mathrm{O} 0.93 \mathrm{mM}$. The seminal plasma was removed by centrifugation at $500 \times \mathrm{g}$ for 15 min and diluted in a Trilady ${ }^{\circledR}$-egg yolk buffer. Prior to cryopreservation, the samples were examined microscopically to determine the sperm volume, concentration, motility, viability, and morphology, and total sperm count by CASA (Medical Supply, Wonju, Korea) using the Food Standards Agency 2011 guidelines. The final diluted semen at the intended concentratio was transferred and sealed in a fresh $50-\mathrm{mL}$ conical tube, stored initially at $25^{\circ} \mathrm{C}$ for $30 \mathrm{~min}$, and then placed in a medium-sized bath container within an icebox $(30 \times 26 \times 15 \mathrm{~cm})$ containing ice slurry for 2 to $3 \mathrm{~h}$ set at $5^{\circ} \mathrm{C}$. Using a low-temperature semen treatment device (FHK, Fujihira Industry, Tokyo, Japan), the cooled, diluted semen was moved to $0.5-\mathrm{mL}$ straws. Then, the semen straws were treated with liquid nitrogen $\left(\mathrm{LN}_{2}\right)$ in a foam box $(26$ $\times 45.7 \times 22.3 \mathrm{~cm}$ ), applying a simple freeze method. The semen straws were placed $5 \mathrm{~cm}$ above the $\mathrm{LN}_{2}$ surface to hold vapors for $10 \mathrm{~min}$. The straws were then immersed into $\mathrm{LN}_{2}$ to cryopreserve the semen. After 3 days of freezing, the cryopreserved semen was thawed in a water bath at $37^{\circ} \mathrm{C}$ for $45 \mathrm{~s}$ for experimental use and AI. For the sperm motility analysis, frozen-thawed semen was 
incubated at $37^{\circ} \mathrm{C}$ for $0,5,60$, or $120 \mathrm{~min}$.

\section{Estrus synchronization and artificial insemination}

The control animals were treated to perform estrus synchronization as follows: sterile saline and $70 \%$ ethanol cotton swabs were used to clean the vulva and Eazi-Breed ${ }^{\mathrm{TM}}$-CIDR (sheep and goat; Zoetis Australia Pty., Rhodes, Australia) was inserted into the vagina for 9 days. On the seventh day post-insertion, $15 \mathrm{mg}$ of $\mathrm{PGF}_{2 \alpha}$ (Lutalyse, Zoetis, Belgium) was injected intramuscularly. Nine days after CIDR insertion, CIDR was removed and 200 IU pregnant mare serum gonadotropin (PMSG) was injected. The AI was performed 24 or $48 \mathrm{~h}$ after PMSG injection. AI was performed and visually confirmed by observing the cervix using equipment that we invented for small domestic animals in the laboratory (Figs. $1 \mathrm{~A}$ and $1 \mathrm{~B})$.

\section{Evaluation of progesterone and estrogen}

To evaluate the P4 and E2 level, blood samples were collected from the jugular vein at around 9 $\mathrm{AM}$ daily for 5 days. Each sample was refrigerated for $12 \mathrm{~h}$ and then centrifuged at $1,000 \times \mathrm{g}$ for $10 \mathrm{~min}$ to separate the serum. The collected serum was stored at $-70^{\circ} \mathrm{C}$ until analysis. The serum concentration of P4 and E2 were evaluated using the electric chemiluminescence immunoassay method.

\section{Pregnancy diagnosis}

To confirm pregnancy, ultrasound (Draminski 4Vet mini, Draminski S.A., Olsztyn, Poland) was used on days 40-60 afterAI. The conception, parturition, and twin fetus parturition rates were analyzed.
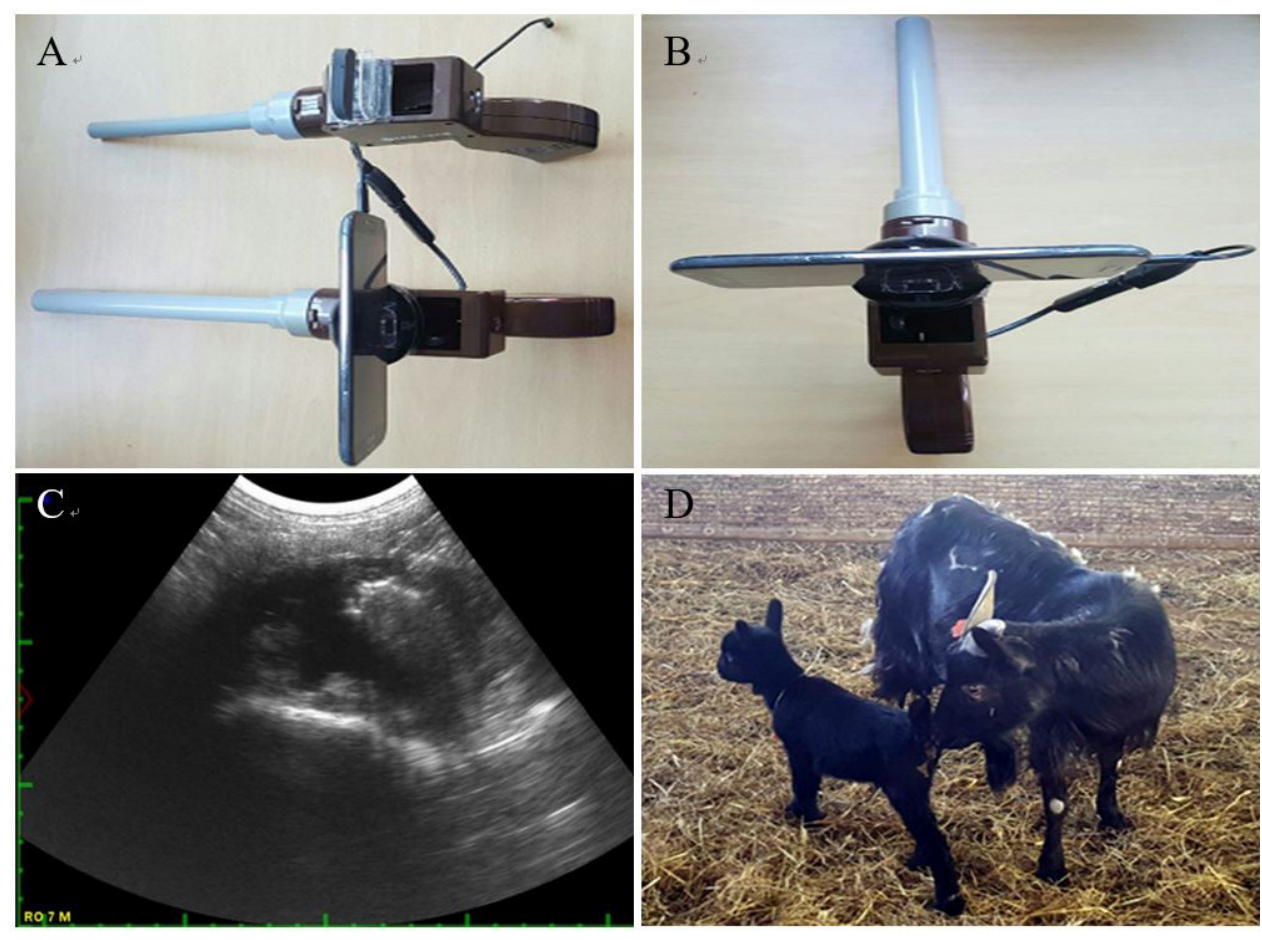

Fig. 1. Artificial insemination (Al) using frozen-thawed semen of the Korean black goat (Capra hircus coreanae). (A), (B) Al instrument for domestic animals. (C) Pregnancy diagnosis by abdominal ultrasonography. (D) A Korean black goat kid obtained by Al using frozen-thawed semen. 


\section{Statistical analysis}

Statistical analyses were performed by using Duncan's multiple range tests using SAS v.9.2. The results with a $p$-value $\leq 0.05$ were considered significant. Inter-group assessments data from all replicates were analyzed using one-way analysis of variance. Depending on the variables, values were represented as the mean $\pm \mathrm{SE}$ or as percentages.

\section{RESULTS}

\section{Semen cryopreservation and thawing}

Semen collection and sperm cryopreservation data were represented in the Table 1 . The percentage of motile sperm was $91.4 \pm 2.4 \%$ after dilution but significantly $(p<0.05)$ declined to $64.2 \pm 7.9 \%$ in frozen-thawed semen samples. However, this did not affect the usage of the sample in AI. Semen motility parameters by using CASA, including total motility, velocity of curvilinear, plenty of lateral head displacement, speed of average pathway, beat-cross frequency, and straightness, were significantly $(p<0.05)$ lower in frozen-thawed semen related to fresh semen (Table 2).

\section{Incubation of frozen-thawed semen}

Frozen-thawed sperm samples were incubated for $0,5,60$, and 120 min at $37^{\circ} \mathrm{C}(p<0.05$, Table 3). Our data demonstrated that, the incubation length negatively affected sperm motility $(64.2 \pm 7.9 \%$, $63.3 \pm 5.8 \%, 49.9 \pm 6.3 \%$, and $35.9 \pm 7.6 \%$, respectively).

\section{Evaluation of progesterone and estrogen levels in the blood}

Variations of $\mathrm{P} 4$ and E2 levels within the blood among estrus-synchronized Korean black goats were represented in Table 4. P4 levels were decreased to less than $1 \mathrm{ng} \mathrm{mL}{ }^{-1}$ after $24 \mathrm{~h}$ of CIDR removal $(9.53 \pm 2.18$ to $0.580 \pm 0.09)$ and gradually decreased up to $96 \mathrm{~h}$. The E2 levels were unchanging even $24 \mathrm{~h}$ after CIDR removal. However, $48 \mathrm{~h}$ and $72 \mathrm{~h}$ after CIDR removal, E2 levels increased. This data help us to get the two distinctive time points for AI; after $24 \mathrm{~h}$ of CIDR withdrawal, as the time at which E2 increases, and after $48 \mathrm{~h}$, as the time at which $\mathrm{P} 4$ decreases.

\section{Pregnancy and parturition rates after Al}

The pregnancy and parturition rates after AI conferring to the method of estrus synchronization are shown in Table 5. Fig. 1C demonstrated the confirmation of pregnancy following 40-60 d after

Table 1. Characteristics of sperm from fresh and frozen-thawed semen (mean $\pm \mathrm{SE}$ )

\begin{tabular}{|c|c|c|c|c|}
\hline \multirow{2}{*}{$\begin{array}{l}\text { Semen volume } \\
(\mathrm{mL})\end{array}$} & \multirow{2}{*}{$\begin{array}{l}\text { Sperm concentration } \\
\left(\times 10^{8} \mathrm{~mL}^{-1}\right)\end{array}$} & \multicolumn{3}{|c|}{ Motile spermatozoa (\%) } \\
\hline & & After collection & After dilution & After frozen-thawed \\
\hline $1.4 \pm 0.7$ & $28.5 \pm 11.6$ & $94.7 \pm 3.2^{\mathrm{a}}$ & $91.4 \pm 2.4^{\mathrm{a}}$ & $64.2 \pm 7.9^{b}$ \\
\hline
\end{tabular}

Experiments were completed with 10 biological replicates.

Values with different superscript ${ }^{\mathrm{a}, \mathrm{b}}$ letters were significantly different $(p<0.05)$.

Table 2. Computer-assisted semen analysis of fresh and frozen-thawed semen (mean \pm SE)

\begin{tabular}{lcccccc}
\hline \multicolumn{1}{c}{ Semen status } & MOT (\%) & VCL $\left(\mu \mathrm{m} \mathrm{s}^{-1}\right)$ & ALH $\left(\mu \mathrm{m} \mathrm{s}^{-1}\right)$ & VAP $\left(\mu \mathrm{m} \mathrm{s}^{-1}\right)$ & BCF $(\mathrm{Hz})$ & STR $(\%)$ \\
\hline $\begin{array}{l}\text { Fresh } \\
\text { (After collection) }\end{array}$ & $94.7 \pm 3.2^{\mathrm{a}}$ & $268.7 \pm 20.8^{\mathrm{a}}$ & $6.5 \pm 0.4^{\mathrm{a}}$ & $139.4 \pm 8.2^{\mathrm{a}}$ & $11.7 \pm 0.2^{\mathrm{a}}$ & $62.1 \pm 4.2^{\mathrm{a}}$ \\
Frozen-thawed & $64.2 \pm 7.9^{\mathrm{b}}$ & $178.9 \pm 13.8^{\mathrm{b}}$ & $4.8 \pm 0.3^{\mathrm{b}}$ & $77.8 \pm 7.3^{\mathrm{b}}$ & $7.8 \pm 0.9^{\mathrm{b}}$ & $51.1 \pm 1.1^{\mathrm{b}}$ \\
\hline
\end{tabular}

Experiments were repeated five times in each group.

Within columns, values with different superscript ${ }^{a, b}$ letters were significantly different $(p<0.05)$.

MOT, total motility; VCL, velocity of curvilinear; ALH, amplitude of lateral head displacement; VAP, velocity of average path; BCF, beat-cross frequency; STR, straightness. 
Table 3. Effect of incubation time on motility of frozen-thawed semen (mean $\pm \mathrm{SE}$ )

\begin{tabular}{|c|c|}
\hline Incubation time (min) & Motility (\%) \\
\hline 0 & $64.2 \pm 7.9^{\mathrm{a}}$ \\
\hline 5 & $63.3 \pm 5.8^{\mathrm{a}}$ \\
\hline 60 & $49.9 \pm 6.3^{b}$ \\
\hline 120 & $35.9 \pm 7.6^{c}$ \\
\hline
\end{tabular}

Experiments were repeated five times.

Within columns, values with different superscript ${ }^{\mathrm{a}-\mathrm{c}}$ letters were significantly different $(p<0.05)$.

Table 4. Changes in progesterone and estrogen levels

\begin{tabular}{|c|c|c|c|c|c|}
\hline \multirow{2}{*}{$\begin{array}{l}\text { Parameter } \\
\left(\mathrm{ng} \mathrm{mL}^{-1}\right)\end{array}$} & \multicolumn{5}{|c|}{ After CIDR removal } \\
\hline & $\mathrm{Oh}$ & $24 \mathrm{~h}$ & $48 \mathrm{~h}$ & $72 \mathrm{~h}$ & $96 \mathrm{~h}$ \\
\hline P4 & $9.53 \pm 2.18$ & $0.580 \pm 0.09$ & $0.316 \pm 0.08$ & $0.259 \pm 0.06$ & $0.255 \pm 0.07$ \\
\hline E2 & $18.9 \pm 5.19$ & $14.0 \pm 2.15$ & $24.2 \pm 3.35$ & $24.4 \pm 6.93$ & $13.3 \pm 2.44$ \\
\hline
\end{tabular}

The experiments were completed within seven biological replicates.

Data were presented as mean $\pm \mathrm{SE}$.

$\mathrm{P} 4$, progesterone; $\mathrm{E} 2$, estrogen; $\mathrm{CIDR}$, controlled internal drug releas.

Table 5. Results of artificial insemination in Korean black goats using frozen-thawed semen

\begin{tabular}{lcc}
\hline Recipient treatment & Pregnancy (\%) & Parturition (\%) \\
\hline Al after 24 h of CIDR removal & 28.6 & 14.3 \\
Al after 48 h of CIDR removal & 42.9 & 42.9 \\
\hline
\end{tabular}

The experiments were completed within seven biological replicates.

$\mathrm{Al}$, artificial insemination; CIDR, controlled internal drug releas.

$\mathrm{AI}$ and pregnancy and fetus status were confirmed by abdominal ultrasonography. The comparison of pregnancy and parturition rates after $\mathrm{AI}$ at $24 \mathrm{~h}$ vs. $48 \mathrm{~h}$ were demonstrated in the Table 5 . Our data highlighted that, $48 \mathrm{~h}$ after CIDR removal group exhibited significantly higher pregnancy and parturition rates. Fig. 1D shows a Korean black goat kid obtained by AI using frozen-thawed semen.

\section{DISCUSSION}

The estrus synchronization protocols before AI differs during the course of the breeding or nonbreeding season. In the breeding season, natural ovulation has to be taken into line, while in the non-breeding season; induced ovulations must be organized accordingly. During the breeding season, the simplest method is to administer two concomitant injections of PGF. Regulatory actions at the time of estrus and ovulation need to be maintained with balance if satisfactory fertility is to be accomplished [18]. The stimulation of estrus synchronisation in small scale or subsistent level thus has a proposed and practical potential for future researchers and farmers. The present study demonstrated the effectiveness of sperm cryopreservation for AI was analyzed in Korean black goats.

In mammalian species, egg yolk and glycerol are conventionally used as cryoprotectants. Egg yolk prevents the dilution and cold shock of changing the sperm membrane [19]. Moreover, egg yolk might be a key factor in sperm cryopreservation, especially stabilization, owing to the inhibition of the acrosome reaction before freezing [20]. Lipase, an important inhibitory factor of sperm viability and cryopreservation, is secreted from the bulbourethral gland in goats but not 
in other livestock [6]. Several studies have investigated the cryopreservation of black goat semen and have shown the survival rate of sperm was ranges from $60 \%$ to $65 \%$ [21], in semen by AI. The present study also found $64.2 \pm 7.9 \%$ sperm motility in frozen-thawed semen (Table 1 ). However, in the consequences of CASA motility parameters (Table 2), were significantly lower in frozenthawed semen compared to fresh semen. This result might be due to the damage by crystallization process during the freezing. The CASA motility parameters of frozen-thawed semen declined, but cryopreserved semen can be used for AI in Korean black goats. Still, further studies are needed to increase the survival rate and motility of sperm for the breeding industry.

Our studies on estrus synchronization has been imposing the optimum protocols to enable favorable synchrony and fertility in Korean black goats, there by generating and introducing simple, practical, and reliable methods for the commercial as well as subsistent farmers. Usually in the commercial goat industry, $\mathrm{FSH}+\mathrm{CIDR}$ or PMSG+CIDR are most commonly used as effective protocols for estrus synchronisation or superovulation [21]. In ruminants, the estrus cycle can be synchronized via the insertion of a P4-impregnated intravaginal device, such as CIDR united with eCG [15]. however, this method cannot synchronize ovulation confidently. Therefore, the present study introduces an estrus synchronization technique ordinarily P4-based synchronization system [5]. After CIDR removal, it was found to be rapidly lowered to less than $1 \mathrm{ng} / \mathrm{mL}$ of P4, and showed a tendency to stay low for about 4 days and gradually increase from the 5 th day after CIDR removal. E2 levels rose sharply after the removal of CIDRs, showing numbers maintained between $24 \mathrm{~h}$ and $48 \mathrm{~h}$. Previous studies highlighted some approaches for estrus synchronization and ovulation for small ruminants [22]. In particular, the synchronizing system using $\mathrm{GnRH}$ and $\mathrm{PGF}_{2 \alpha}$ has been shown to synchronize the pre-ovulatory surge in gonadotropin, allowing ovulation to be relatively synchronous in cows $[4,5]$. In addition, the $\mathrm{GnRH}_{-}-\mathrm{PGF}_{2 \alpha}$-based synchronization method is applicable for the AI of dairy goats and has been compared to CIDR-based treatments for dairy cows in a previous study; thus, the combination of $\mathrm{P} 4$ and a GnRH-PGF ${ }_{2 \alpha}$-based program may increase the pregnancy rate [23].

Our data accompany [24] who demonstrated intravaginal P4 treatment (CIDR) for 5-days in which $\mathrm{PGF}_{2 \alpha}$ is administered on the day of sponge insertion, and removal of eCG (400 IU) by sponge. He mentioned that, the LH level becomes peak at $40 \mathrm{~h}$ after treatment withdrawal. Subsequently AI was performed at around $54 \mathrm{~h}$ and consequences good fertility [24]. Other researchers mentioned alternative protocols for inducing synchronization and fixed-time AI and was directed to reduce the use of hormones, especially those that leave residues, while maintaining the degree of synchronization and ovulation [24]. Several other studies have investigated estrus synchronization protocol in ruminants, including cows, dairy cows, sheep, and goats. In the present study, blood hormone levels remained similar across treatments: the P4 level remained less than $1 \mathrm{ng} \mathrm{mL}{ }^{-1}$ for $4 \mathrm{~d}$ and the E2 level increased for a 2-d period. The effectiveness of fixed-time AI should be determined by confirming the optimum interval between the end of synchronization treatment and AI. The best way of establishing the optimum time for AI could be accomplished by confirming the preovulatory $\mathrm{LH}$ surge after synchronization. The farmers have to keep in mind that the time between the onset of estrus and the presence of the preovulatory $\mathrm{LH}$ surge besides comparatively $22 \mathrm{~h}$ between the ovulation.

Moreover, hormonal variation data could be useful key to predict ovarian follicle status. Our results showed that the parturition rate was optimal whenAI was performed $48 \mathrm{~h}$ after CIDR removal and PMSG injection. A kid from an estrus-synchronized Korean black goat was successfully produced by AI using frozen-thawed semen. Our data indicate that estrus synchronization methods should be used separately from AI. If these methods are used prior to AI, other programs with modified AI timings based on hormone levels will be necessary. 
However, previous studies have revealed that, after $\mathrm{PGF}_{2 \alpha}$ treatment, ovarian follicle becomes a dominant mature follicle and after ovulation, the P4 level decreases significantly owing to corpus luteum regression. Follicular growth then continues, and a pre-ovulatory follicle grows. $\mathrm{GnRH}$ injection reinitiates the pituitary release of $\mathrm{LH}$ and pre-ovulatory follicle ovulation. Therefore, the period of 16-20 h after GnRH injection might be suitable for AI [25-27]. Previous studies with ovariectomized ewes were inserted with CIDR devices, plasma $\mathrm{P} 4$ get peaked within $2 \mathrm{~h}$ of insertion $(5.5 \mathrm{ng} / \mathrm{mL})$, while a rapid curvilinear decline happens thereafter [28]. But, subsequent studies by Wheaton and coworkers [29], found peak plasma P4 values of $2.1 \mathrm{ng} / \mathrm{mL}$ within $24 \mathrm{~h}$ and was comparatively stable levels between $\mathrm{d} 1$ and $13(1.9 \mathrm{ng} / \mathrm{mL})$. They hypothesize the standard protocols for the usages of CIDR devices are typically identical to protocols for intravaginal sponges. Furthermore, [30], advising to reduce the dose of $\mathrm{P} 4$ had little effect on fertility.

Finally, provision of estrus synchronisation with subsequent AI (by using fresh or frozen semen) has been increasing and perhaps would be the most powerful tool for the reproductive biotechnologist and also will provide the Korean black goat industry with enlightening reproductive efficiency and genetic up-gradation. One of the most exciting developments would be possible in the reproduction of Korean native black goats by combining estrus synchronization with AI.

\section{CONCLUSION}

In conclusion, successful estrus synchronisation with AI by using Korean native black goat's semen was confirmed by sperm motility and pregnancy rate. We hope that these studies contribute to the Korean black goat's breeding industry and also suggest indications regarding estrus synchronisation with subsequent $\mathrm{AI}$ and also overcome the constraints that lead to infertility. Further studies are going on regarding establishment of a trustworthy estrus synchronization protocol for the AI of Korean native black goats.

\section{REFERENCES}

1. Chowdhury MMR, Xu L, Kong R, Park BY, Mesalam A, Joo MD, et al. In vitro production of sex preselected cattle embryos using a monoclonal antibody raised against bull sperm epitopes. Anim Reprod Sci. 2019;205:156-64. https://doi.org/10.1016/j.anireprosci.2018.11.006

2. Zhao Y, Zhang J, Wei H, Sun X, Mu B, Yu M. Efficiency of methods applied for goat estrous synchronization in subtropical monsoonal climate zone of Southwest China. Trop Anim Health Prod. 2010;42:1257-62. https://doi.org/10.1007/s11250-010-9558-6

3. Baldassarre $\mathrm{H}$, Karatzas $\mathrm{CN}$. Advanced assisted reproduction technologies (ART) in goats. Anim Reprod Sci. 2004;82-3:255-66. https://doi.org/10.1016/j.anireprosci.2004.04.027

4. Pursley JR, Mee MO, Wiltbank MC. Synchronization of ovulation in dairy cows using PGF2 $\alpha$ and GnRH. Theriogenology. 1995;44:915-23. https://doi.org/10.1016/0093691x(95)00279-h

5. Holtz W, Sohnrey B, Gerland M, Driancourt MA. Ovsynch synchronization and fixed-time insemination in goats. Theriogenology. 2008;69:785-92. https://doi.org/10.1016/j.theriogenology.2007.10.004

6. Leboeuf B, Restall B, Salamon S. Production and storage of goat semen for artificial insemination. Anim Reprod Sci. 2000;62:113-41. https://doi.org/10.1016/S0378-4320(00)00156-1

7. Bogdan L, Groza I, Ciupe S, Neagu R, Tutulan C, Petrean A, et al. Research concerning estrus induction and synchronization in anestrous (out of season) goats. Vet Med. 2008;65:91-5. https://doi.org/10.15835/buasvmcn-vm:65:2:1535 
8. Martínez MF, Kastelic JP, Colazo MG, Mapletoft RJ. Effects of estradiol on gonadotrophin release, estrus and ovulation in CIDR-treated beef cattle. Domest Anim Endocrinol. 2007;33:77-90. https://doi.org/10.1016/j.domaniend.2006.04.009

9. Manjarin R, Dominguez JC, Castro MJ, Vallado B, Rodriguez S, Sprecher DJ, et al. Effect of prior FSH treatment on the estrus and ovulation responses to eCG in prepubertal gilts. Anim Reprod Sci. 2009;110:123-7. https://doi.org/10.1016/j.anireprosci.2008.01.001

10. Kusina NT, Tarwirei F, Hamudikuwanda H, Agumba G, Mukwena J. A comparison of the effects of progesterone sponges and ear implants, PGF2alpha, and their combination on efficacy of estrus synchronization and fertility of mashona goat does. Theriogenology. 2000;53:1567-80. https://doi.org/10.1016/s0093-691x(00)00298-3

11. Leboeuf B, Forgerit Y, Bernelas D, Pougnard JL, Senty E, Driancourt MA. Efficacy of two types of vaginal sponges to control onset of oestrus, time of preovulatory LH peak and kidding rate in goats inseminated with variable numbers of spermatozoa. Theriogenology. 2003;60:1371-8. https://doi.org/10.1016/s0093-691x(03)00149-3

12. Twagiramungu H, Guilbault LA, Dufour JJ. Synchronization of ovarian follicular waves with a gonadotropin-releasing hormone agonist to increase the precision of estrus in cattle: a review.J Anim Sci. 1995;73:3141-51. https://doi.org/10.2527/1995.73103141x

13. Nebel RL, Jobst SM. Evaluation of systematic breeding programs for lactating dairy cows: a review.J Dairy Sci. 1998;81:1169-74. https://doi.org/10.3168/jds.s0022-0302(98)75679-6

14. Miura H, Kotani S, Kohiruimaki M, Ohtsuka H, Kikuchi M, Ohnami Y. Relationships between the conception rate of estrus synchronization using estradiol benzoate and CIDR (progesterone) and other parameters in Holstein lactating dairy cows.J Reprod Dev. 2008;54:2146. https://doi.org/10.1262/jrd.18084

15. Long ST, Nakao T, Wakatake S, Okakoi M. Effect of CIDR 12 to 19 days after AI on detection of returning estrus and conception rate in dairy cows. J Reprod Dev. 2010;56:251-5. https://doi.org/10.1262/jrd.09-134t

16. Azevedo C, Maia I, Canada N, Simões J. Comparison of fertility, regular returns-to-estrus, and calving interval between Ovsynch and CO-synch + CIDR protocols in dairy cows. Theriogenology. 2014;82:910-4. https://doi.org/10.1016/j.theriogenology.2014.07.006

17. Stelletta C, Tekin K, Tirpan MB, Alemdar H, Cil B, Oztutar Stelletta F, et al. Vulvar thermal pattern following synchronization of estrus is linked to fertility after timed artificial insemination in goat. Theriogenology. 2017;103:137-42. https://doi.org/10.1016/j.theriogenology.2017.07.038

18. Rahman ANMA, Abdullah RB, Wan-Khadijah WE. Estrus synchronisation and superovulation in goats: a review.J Biol Sci. 2008;8:1129-37. https://doi.org/10.3923/jbs.2008.1129.1137

19. Quinn P, Stanger JD. Effect of purification of bovine serum albumin on the interaction of human semen with mouse ova in vitro. Biol Reprod. 1980;22:134-40. https://doi.org/10.1095/ biolreprod22.2.134

20. Witte TS, Schäfer-Somi S, Kuchar A, Möstl E, Iben C, Aurich C. Effect of hen's egg yolk on capacitation and acrosome reaction of diluted canine spermatozoa. Anim Reprod Sci. 2009;110:293-305. https://doi.org/10.1016/j.anireprosci.2008.01.022

21. Luo J, Wang W, Sun S. Research advances in reproduction for dairy goats. Asian-Australas J Anim Sci. 2019;32:1284-95. https://doi.org/10.5713/ajas.19.0486

22. Titi HH, Kridli RT, Alnimer MA. Estrus synchronization in sheep and goats using combinations of GnRH, progestagen and prostaglandin F2 $\alpha$. Reprod Domest Anim. 2010;45:594-9. https://doi.org/10.1111/j.1439-0531.2008.01309.x

23. Stevenson JS, Pursley JR, Garverick HA, Fricke PM, Kesler DJ, Ottobre JS, et al. Treatment 
of cycling and noncycling lactating dairy cows with progesterone during Ovsynch.J Dairy Sci. 2006;89:2567-78. https://doi.org/10.3168/jds.S0022-0302(06)72333-5

24. Menchaca A, Rubianes E. Pregnancy rate obtained with short-term protocol for timed artificial insemination in goats. Reprod Domest Anim. 2007;42:590-3. https://doi.org/10.1111/ j.1439-0531.2006.00827.x

25. Pursley JR, Wiltbank MC, Stevenson JS, Ottobre JS, Garverick HA, Anderson LL. Pregnancy rates per artificial insemination for cows and heifers inseminated at a synchronized ovulation or synchronized estrus. J Dairy Sci. 1997;80:295-300. https://doi.org/10.3168/jds.s00220302(97)75937-x

26. Geary TW, Whittier JC, Downing ER, LeFever DG, Silcox RW, Holland MD, et al. Pregnancy rates of postpartum beef cows that were synchronized using Syncro-Mate-B or the Ovsynch protocol.J Anim Sci. 1998;76:1523-7. https://doi.org/10.2527/1998.7661523x

27. Stevenson JS, Kobayashi Y, Thompson KE. Reproductive performance of dairy cows in various programmed breeding systems including Ovsynch and combinations of gonadotropin-releasing hormone and prostaglandin F2 $\alpha$. J Dairy Sci. 1999;82:506-15. https://doi.org/10.3168/ jds.s0022-0302(99)75261-6

28. Ainsworth L, Downey BR. A controlled internal drug-release dispenser containing progesterone for control of the estrous cycle of ewes. Theriogenology. 1986;26:847-56. https://doi. org/10.1016/0093-691X(86)90014-2

29. Wheaton JE, Carlson KM, Windels HF, Johnston LJ. CIDR: a new progesterone-releasing intravaginal device for induction of estrus and cycle control in sheep and goats. Anim Reprod Sci. 1993;33:127-41. https://doi.org/10.1016/0378-4320(93)90111-4

30. Vilariño M, Rubianes E, Menchaca A. Re-use of intravaginal progesterone devices associated with the short-term protocol for timed artificial insemination in goats. Theriogenology. 2011;75:1195-200. https://doi.org/10.1016/j.theriogenology.2010.11.030 